\title{
Use of Innovative Technologies in Training of Future Social Workers
}

\author{
Valentyna Sanzharovets ${ }^{1}$, Tetyana Petrenko ${ }^{1}$, Iveta Mietule ${ }^{2}$, Larysa Platash $^{3}$ and Liubov Kostyk ${ }^{3}$ \\ ${ }^{1}$ National Aviation University, 1 Liubomyra Huzara ave., Kyiv, Ukraine \\ ${ }^{2}$ Rezekne Academy of Technologies, 115 Atbrivosanas aleja, Rezekne, LV-4601, Latvia \\ ${ }^{3}$ Chernivtsi National University named after Yuriy Fedkovich, Kotsyubynskoho St., 2, Chernivtsi, 58012, Ukraine
}

\begin{abstract}
The article considers the actual problem of using the innovative technologies during the educational process in higher education institutions for training of future social workers. Professionalism in the activities of a social worker is in constant motion. Actions that take place in a society require constant professional changes in methods and technologies of social work. Social work is inseparable from society as a whole and is aimed at the population. Designing in social work is a constructive, complex, creative activity, the essence of which is in advanced reflection of reality in order to transform the personality of oneself, own life situation and the surrounding world with the help of a social worker. Social work refers to the category of innovative, creative technologies, because it involves a change of reality. It is based on the existing life situation, which can be unified, mastered and refined. A social worker is the initiator of innovation, the purpose of which is to create, modernize or maintain in a changed environment material or spiritual value of people, recognized as positive in its social value.
\end{abstract}

\section{Introduction}

Modern Ukraine, during the period of its development, requires higher education sphere to prepare a free, socially active, communicative, responsible, professionally trained person, capable of self-development and a specialist who knows his own path, chooses it consciously and responsibly. The training of such specialists requires the use of the latest technologies and teaching methods in the educational and pedagogical process of higher education institutions.

The formation of professional social work in our country is associated with the search for new approaches, development, implementation of innovations in the life of society and activation of innovative processes in the social sphere. This is especially important in today's socio-economic conditions of the cardinal renewal of all life's foundations, of the need to adapt a person to everchanging circumstances and for his effective social protection.

Today, the world is experiencing crisis phenomena that have affected all spheres of human life without exception. Thus, it should be noted that economics, politics and culture are three interdependent levers: the development of one of them promotes the development of the other two and vice versa - the inhibition of at least one has the effect of total destructive processes.
Moreover, constructive or destructive processes in these areas affect the life of society as a whole and the individual in particular.

Social work, as defined by the European Association of Schools of Social Work, is an academic discipline and professional activity that promotes social change and development, social cohesion, and the empowerment and independence of individuals, involving individuals, groups, and societies to the deciding the problems of persons and families who are in difficult life circumstances and improving the quality of their lives and wellbeing, on the principles of social justice, respect for human rights, collective responsibility and respect, counteracts the factors of social exclusion and promotes respect for human rights.

The most important goal of social policy is to ensure more complete satisfaction of the members of society with their vital needs, because it is on this occasion that social relations are formed in the first place, and it is on this basis that the social reproduction of social groups and individuals takes place. At the same time, when it comes to meeting the vital needs of people in the implementation of social policy, we mean their satisfaction is not through the own efforts of members of society. Social policy embodies society's concern for people in need of support and assistance. In other words, social policy is aimed at providing assistance and support to people from the social system in which they belong, by using the social potential available in the relevant social system. 
However, it should be noted that the main purpose of social work is to promote the normalization of human life, meet and harmonize its social needs, harmonize the needs of the individual and society.

Today, society has many theories of art and creativity, which help to see beyond the standard look at existing problems and offer their nontraditional solutions. The basic preconditions for creative work, the development and implementation of innovations in the field of social work are social needs, as well as social problems. These arise in the life of society, its individual layers and individuals, and require for its solution new forms, methods, means, models, programs and projects of social work and social assistance.

\section{Theoretical Aspects of a Research}

Students of higher education institutions are graduates of the 11th form, which can be attributed to the youth. Juvenile age is the most sensible in terms of upbringing respect, self-esteem and its development, etc. Young people of this age are trying to grasp the basic principles and laws of morality, to deduce the basic rules of living together in society. At the same time, young people tend to overestimate the level of their own knowledge and abilities, while their life orientation is not yet well-formed. Here is "Me" blurred, while continuing to seek their own identity.

The peculiarity of adolescence is vulnerability and inconsistency in judgments, vital observations and conclusions. Children of this age combine high demands on others (parents and teachers) and uncritical attitude towards oneself, their own thoughts, actions.

For primary school students, there are typical crises that are explained by changes in social status, adaptation to new conditions of life, new rights, demands and responsibilities, namely:

$\checkmark$ The crisis of professional choices, based on the dissonance between the unconsciously chosen profession and the need for education;

family;

$\checkmark$ crisis of dependence on the parent's

$\checkmark$ crisis of intimate-sexual relations;

$\checkmark$ identity crisis.

In this situation, young people need appropriate support and assistance from parents and teachers. An important factor in the education of self-esteem among young people is the formation of a demanding to oneself, which determines not only self-knowledge, self-esteem, but also the desire to work on oneself, the self-realisation, including in the professional sphere. In order to feel confident in a situation of constant change and to respond adequately to them, the social worker must increase his creative potential, be able to help the client to activate his creative skill and to direct them to solve the problem. All this determines the task of professional training of a social worker - the development of a future specialist, ready for the creative exercise of professional activity.

Social workers and social specialists provide advising and counseling to individuals, families, groups, communities and organizations in the event of social and personal difficulties. They help clients develop the necessary skills and provide access to appropriate resources and support services needed to respond to problems related to unemployment, poverty, disability, addiction, deviant behavior, including criminal, family problems, etc.

Their main tasks are:

- conducting an assessment of the needs of social services clients;

- interviewing clients individually, as a family or in groups, to assess their condition and problems, as well as to determine the necessary services;

- analysis of the client's situation and identification of alternative approaches to solving problems;

- provision of social services to their recipients in accordance with the concluded agreement on the provision of social services and individual plan; - providing counseling, mediation services, group classes to assist clients in developing the necessary skills and knowledge needed to solve their own social and personal problems;

- planning and implementation of client assistance programs, including crisis intervention and referral to institutions that provide financial and legal assistance, housing, medical treatment and other services;

- participation in the investigation of cases of negligence or abuse and taking measures to protect children and others at risk;

- representing the interests of different groups of clients in the community, as well as lobbying to address the problems they face;

- development of prevention and intervention programs to meet the needs of the community;

- liaising with other social, educational and health care providers who work with clients to provide information and provide feedback on the general condition of clients and their achievements, etc .;

- formation of publicly available information resources that contain information about the activities of social service providers and provide access to these resources by placing them on information stands in the premises of social service providers, in the media, on the Internet.

Professional training of specialists in social work is based on qualification requirements that combine professional competence, intellectual, personal and moral qualities, which are an indicator of the success and effectiveness of their activities. Representatives of this profession must have the established moral qualities and properties, because it is morality that regulates the human relations between people in different situations on a democratic basis.

Morality, as spiritual quality of a person, the need to bring good to people, is the basis of the personality of a social worker, and it is trained during the educational process in higher 
educational institutions. These are the moral qualities of a specialist that largely determine the behaviour of the client, his social well-being and psychological state. And this, students can learn while studying the subjects "Social work with Families", "Social work with different groups of customers", operating with the Code of Ethics of a social worker.

By teaching disciplines, we offer students to fill the wheel of moral qualities, and to specify the main eight qualities of a specialist. The student first assesses how many points, according to this personal point of view, this quality is important. Then the person assesses the number of points, which specify the presence of this feature in itself. Often between the desired and available there is a difference in a certain number of points. Everyone then determines what needs to be done to become kinder, more tolerant, etc. That is how we start the path towards improving or gaining the moral qualities of a future specialist.

The main ethical principle of social worker's activity is respect for the dignity of every person. The principle of respect for the dignity of each person should be understood as a special moral attitude towards the person, recognition of his rights and opportunities.

Students can be offered the following form of work. Each participant determines the main moral quality that he considers necessary for a decent living, work, communication with the environment, and writes a statement on paper using a certain feature. Then I change the sheets, and the students get notes of another. The task before us - is to reveal the content of the sentence. For this we can suggest to come up with a story or to give an example. Next we compare the written content with the idea, which was enclosed in the statement, first source.

Disturbance against human dignity are physical violence, disrespectful attitude, injustice, inequality, rudeness, psychological pressure and trauma, etc. Every person is extraordinary and unique, which must be taken into account by social workers without any manifestation of disregard for the individual. Everyone has the right to selfrealization, which does not lead to a violation of similar rights of other people. Social work is incompatible with direct or indirect coercion of clients to any action, even in favour of the client or his close social environment.

Communication with the client is the integral part of social worker's activity. Unfortunately, we often see a decline in the culture of communication. We often see professionals who are impatient with clients with special needs, the elderly, and whose communication does not seem to look like civilized [8].

Studying with students "Social Gerontology", we offer them to prepare proverbs and sayings about old age and elderly age, to pick up excerpts from the works of art we discuss. Students are offered to make a conclusion about the attitude towards the elderly people, to provide forms of work with the gerontological group of the population.

The effectiveness of social work depends not only on professional attitude to the customer, but also on the attitude to oneself. Only those who respect themselves are fair and respect others. Word is a way of communicating with others, the way of transmitting information, own thoughts, desires and requests. The word can get you interested, cheer up, heal. Each spoken word has a different level of vibration and has a certain energy and emotional appeal. Words of a social work specialist are a powerful tool that affects the level of personal energy of the client, emotional balance and health. Words with low vibrations, negative references that restrict beliefs negatively affect the state of health and human behaviour. The first step is to fill life with words with high vibrations is awareness. Through the customer's observation of his phrases, which he describes himself or his life, the social worker determines the methods and technologies that will be used in his work in the conduct of the case. A person who is accustomed to inventing others in his own failings sees only the injustice of destiny and does not pay attention to his own disadvantages needs special attention. Therefore, in order to change the internal world of such a client, it is necessary to start with value orientations, to pick up special words, signs, focusing on the perfection of the individual. The words of the social worker are the paint he applies and teaches with the help of creativity and meditations to expand the client's outlook. Intelligently and consciously choosing methods of creativity in social work are needed for client to realize his life and desire to change it. [6].

A social worker has to deal with different categories of clients, and regardless of age, social status, financial position, the social worker should place the client's personality and his interests in the centre of his professional activity. Adherence to the principles of a person-oriented approach, the creation of a supportive atmosphere in the learning process will allow not only to develop the students' creative abilities, but also to transfer to future specialist practical principles of working with people aimed at creating favourable conditions for a person. Customer orientation is one of the important principles of social work. Such interaction with students should be learned not only in theory, but also in practical examples, based on their experience.

Creativity, i.e. the ability to creativity, the culture of social work is so clearly and distinctly characterized. "Creativity" in its very first meaning is the creation of a new person.

The social worker, who addresses to the problem of creativity, thinks in the categories of "eternity" and "beginning". Creativity in terms of social work is the life force, the ability of a specialist - as the bearer of culture to respond to the challenges of time. 
The tasks of social work are:

1. Obtaining necessary knowledge in the field of creative and innovative activities in the social work system.

2. Mastering the experience of innovation activities, development and implementation of social projects.

3. Development of the autonomy of thinking in the light of obtaining new knowledge in the field of the theory of creativity and spirituality.

From the doctrine of Volodymyr Vernadsky for social work, it is clear that the spirituality of man carries a distinct imprint of social existence, as all practical actions of human are the individual expression of historically composed social practices of mankind. In an explicit and implicit way, the noosphere idea is presented in various aspects and continues in the studies of the 20th century. It is submitted that the distinction between traditional societies and modern changes is connected by changes in the field of methods and technologies, science and scientific innovations, which inevitably entails the change of all other spheres of human life.

\section{Results and discussion}

Every new rethinking of the radical concepts of social organization and development of social relations always piques interest and is the subject to lively discussions. And if society was studied as a phenomenon without an external mental environment - immersion in the meta-spiritual sphere, then with the discovery of the intelligent universe - the noosphere, obviously there happens a coup in the human thought. According to Vernadsky, society is the only social organism whose internal organization is a set of definite, characteristic various relationships, in which the human mind is involved. Particularly characteristic is Vernadsky's metaphorical description of the social life of a person, which is as impossible outside the society, as the life of a plant, pulled from the ground and thrown into dry sand. Public life penetrates through the psychic inside the biology of the individual, which in such a transformed form acts as the basis of his mental, conscious life.

Famous Stanislav Losev is valeologist of the master class, specialist of the international level, his methods are approved by the International scientific practical conferences and tested by many years of practice. He, as a member of the National Union of Writers of Ukraine constants: "At the university, we established a clear pattern between the psychological state of man and his fate: if the son is offended by his father - he will not have normal professional activity. If by his mother - he will never create a normal family life. And here we learned how to work with these programs and to correct them with key phrases. In life there is no reason to be unhappy. The most complicated conflicts and failures of life are only the possibility of nature to awaken man to action. Moreover - the stronger the opportunities of the individual - the more difficult the circumstances that make him or her act in the right direction" [2].

The whole system of relations with the world in spiritual culture is distributed in the base matrix, which allows the social experience to be broadcasted, closing it and introducing into the matrix of a social unit, such as personality. Modern practical science has proved that our thoughts are "alive" and they can be heard. Every time a person thinks about something, he emits a specific vibrational energy. Thoughts have different vibrations and strength. The more energy a certain thought has, the greater its strength and the ability to attract different events in our reality. In accordance with the law of attraction, energy attracts energy. Therefore, a person attracts to oneself the circumstances, events and people who are at the level of the dominant vibrational frequency. Understanding that people form their own thoughts around reality will help them make decisions and start living on high vibrations. The more goodness and light a person brings into the world - the more attracts. With this method, a social worker will help the client change its life circumstances, look at them from another direction and understand the best life scenario for him.

One of the first commandments of a social worker is "a glass of cold water, timely submitted to the traveller is more valuable and noble than a dozen lunches donated to a person who can afford to pay for them". Here is bearing in mind the practical philanthropy, spirituality and creativity, which is the starting point in the search for ways and leverage to achieve the goals. It is through selfesteem that the system of human values or desires in life is determined. Self-esteem is an interesting system phenomenon which attributes the value ascribed to the individual based on various parameters. The time that a person, social worker gives another person is invaluable. It's impossible to return it, so it's so important to take care of it. Following the commandments of philosophy, a thinking and enlightened social worker will be able to understand the truth and help people, groups and communities. Generating the enthusiasm of a specialist in social work, and "enthusiasm", says Edward Bulwer-Lytton, "is a spirit of sincerity and truth ...". Actions in human life mean more than words and they even make humans worthy. There are laws of the universe that work when a person is disappointed. It may be due to the fact that person thinks the world is guilty of something. Life, by its nature, is not just or unfair. Life is just life. The quality of our live is determined not by external factors, but by the way we perceive them. Release those things that have already served, or are beyond our control. It is from this position that a social worker is asked to create the reality of the client. No one can take more than he can have, whether it is love, devotion, time, work or money. Thus, the 
social worker must have the knowledge, skills and abilities that can give the client a solution to life issues.

Students are invited to learn and develop using metaphorical associative cards and board games. The cards are created as a social worker tool. Each card provides answers to the most important questions of social work clients. With the help of the proposed drawings, the specialist has the opportunity to awaken the client's imagination, the subconsciousness and to contribute to solving his psychological problems. They can be used during diagnostic, educational, training, consulting work, etc. A set of proposed cards and techniques for working with them are presented in a way that it can be used in the work as by professional social workers, helping clients to solve their life difficulties, promote their personal growth, also by the people without special education who are willing to use this kit for self-development and selfimprovement. Working with the $\log$ of metaphorical associative cards "Know Yourself and the World", you can use different techniques, namely: "Who am I?", "Communication", "Technique of fulfilling the desired", "The Wheel of Life", etc.

By mastering the technique "Who am I?", the client randomly selects from the log five cards that correspond to his status in the past, in the present and in the future, also how people perceive the person and what person wants to be. Then it is suggested to compare the cards, find common and different. The conclusion is that a person wants to change oneself. If work is conducted with children, then they can be offered to make a fairy tale or story about the heroes in cards.

In the "Communication" technique, the client is offered to select two cards, which he associates with his friend and with the person who has problems in communicating. Then cards are selected that are associated with the emotions that arise in the process of communication. You can choose two more cards that will show how the client wants to be perceived, etc. [7].

Working with "difficult" teenagers one can use the technique of "Work with the problem" where you offer to form a problem or question, then to choose three random cards. Considering each card one can interpret what blocks solving the problem, what can help and what you do to solve the problem.

Thus, one of the main tasks of professional education at the present stage is not only the transfer of knowledge, skills and abilities in the process of professional training, but also the development of the personality traits of the future specialist. Formation of a world-view based on multi-vector solutions, desire to move away from stereotypes in thinking, tolerance to thoughts dissimilar to their own, largely determines the creativity of the future specialist in social work.

Leo Vygotsky wrote on the problem of creativity: "Creative activity we call such activity of a person who creates something new. It is the creative activity of man that makes it a human being drawn to the future, creates it and modifies it".

\section{Conclusion}

Almost every person in modern society falls into difficult living conditions, where her psyche faces the impossibility of rethinking and adequately responding to a problematic stressful situation. That is, falling into an unusual, extreme, extraordinary situation depends on the personal organization, how the person will react to what has happened. Client of social work (man caught in difficult life circumstances) - as a collective individual acquires various social roles, that's why social work is the best possible indicator of creative energy and a social worker - is the specialist with the methods and technologies and the necessary knowledge to help people.

So, the future specialist in the social sphere must combine professional and moral values, have the knowledge, skills and abilities, be a true professional. Therefore, the task of teachers of higher educational institutions is in the creative approach to the process of education and training, in the use of innovative technologies in the pedagogical process.

Thus, in the process of revival and constructive changes required by the very objective reality and actuality, social work, as a science, as a type of professional activity, as an academic discipline, plays an extremely important role. A special role is given to social workers who receive professional education in higher education, differ in their views on a particular social problem or situation, which allows them to find the most effective ways to overcome them.

The progressive changes taking place in society today, on the one hand, promote self-disclosure, self-determination and self-affirmation of man, on the other - reveal a lack of goodness and mercy.

\section{References}

1. Alston M. Social work, climate change and global cooperation // International Social Work. 2015. Vol. 58(3). P. 355-363.

2. Findley P. A., Pottick K. J., Giordano S. Educating Graduate Social Work Students in Disaster Response: A Real-Time Case Study // Clinical Social Work Journal. 2017. Vol. 45:2. P. 159-167.

3. Harris C., \& Boddy J. The Natural Environment in Social Work Education: A Content Analysis of Australian Social Work Courses // Australian Social Work. 2017. Vol. 70 (3). P. 337-349.

4. Petrenko. T. Sanzharovets V. Modern technologies in the training of social 
specialists. Bulletin of the National Aviation University. Series: Pedagogy.

Psychology: Collected Science Ex-K: National Aviation University, 2018.-Issue 2 (13) .- 38 p.

5. Lombard A. Global agenda for social work and social development: A path toward sustainable social work // Social Dialogue. 2016. Vol. 14. P. 6-15.

6. Ganna Koval, Valentina Sanzharovets and Yulia Shatylo 2020 Social Works in Certain Areas of Donetsk and Lugansk Regions 2020 III International Scientific Congress Society of Ambient Intelligence 2020 (ISC-SAI 2020). Atlantis Press. Advances in Economics, Business and Management Research 129, 361-369 doi:10.2991/aebmr.k.200318.045

7. Sanzharovets V. and Shatylo Y. 2020 Psychological features of the development of communicative negotiation skills in future social workers. Scientific journal of the National Pedagogical University names M P Drahomanov Series 12 Psychological sciences: Collection of Scientific Works. (Kyiv: Publishing house of NPU names M.P. Drahomanov) Vol 10 (55) $151 \mathrm{p}$ doi: https://doi.org/10.31392/NPUnc.series 12.2020.10(55).10

8. Sanzharovets V. Features of pedagogical methods of social work with military personnel. Bulletin of the National Aviation University. Series: Pedagogy. Psychology -K., 2017.-Issue 2 (11). - 192s.

9. Semigina $T$. International social. robot: global priorities of social development and innovations of social robot // Bulletin of APSV. 2015. No. 1. S. 6-11.

10. Nesmith A, Smyth N. Environmental Justice and Social Work Education: Social Workers' Professional Perspective // Social Work Education. 2016. Vol. 34:5. P. 484-501. 66.

11. Nikku B. R. Living through and responding to disasters: Multiply roles for Social Work // Social Work Education. 2015. Vol. 34:6. P. 601-606.

12. Teixeira S., Krings A. Sustainable Social Work: An Environmental Justice Framework for Social Work Education // Social Work Education. 2015. Vol. 34(5). P. 513-527.

13. Dominelly, L., ed. (2018). The Routledge Handbook of Green Social Work. Abingdon: Routledge. 2018. 628 p.

14. Platash LB, Prodanchuk T. Professional training of social workers as a scientific problem / Science of the third millennium: searches, problems, prospects of development: materials of the II International scientific-practical Internet conference (April 25-26, 2018): collection of abstracts. - Berdyansk: BSPU, 2018. Part 1.- 333 p. - P. 251-252. 